\title{
RETRACTED ARTICLE: Seasons
}

\author{
Jonathan Reisman
}

Published online: 7 September 2010

(C) Springer Science+Business Media, LLC 2010

\section{RETRACTED ARTICLE: J Med Humanit DOI 10.1007/s10912-010-9122-4}

This poem is a duplicate version of another poem entitled "Seasons" written by the same author that is included in the article entitled "For There is Work to be Done: Poetry and Commentary" published in Journal of Medical Humanities, Volume 32, Issue 3, pages 245250, DOI: 10.1007/s10912-011-9141-9. Editor-in-Chief Therese Jones apologizes to the readers of the journal for not detecting this duplication during the publishing process. The online version of this article contains the full text of the retracted article as electronic supplementary material.

Electronic supplementary material The online version of this article (doi:10.1007/s10912-010-9122-4) contains supplementary material, which is available to authorized users.

\footnotetext{
J. Reisman $(\bowtie)$

6 Brewer Street, \#3, Cambridge, MA 02138, USA

e-mail: reisman.jonathan@gmail.com
} 